\title{
From 'intercultural-washing' to meaningful intercultural education: Revisiting higher education practice
}

The Editorial by Mélodine Sommier ${ }^{1}$, Malgorzata Lahti, and Anssi Roiha

This is the first special issue that JPHE hosts - and could there be a more suitable forum for an issue dedicated to exploring and encouraging a critical dialogue around transformative intercultural communication teaching practices in higher education (HE)? What has led us to engage with the theme of making intercultural education meaningful is a shared observation that there seems to be an increasing disconnect between recent developments in intercultural communication theory and practice. With so much critique published over the years, we are perplexed as to why traditional notions of culture still prevail not only in mainstream intercultural communication research but also in institutional discourses in $\mathrm{HE}$ and in popular discourses as articulated by the people who sit-or have once sat-in our classrooms. In this editorial and Special Issue, we approach intercultural communication from a critical angle, akin to the theorization of interculturality as a discursive and contingent, unstable and contradictory, political and ideological construct. We are thrilled to see this approach gain ground in the field of intercultural communication. However, at the same time, we are worried that the terrain of intercultural communication teaching across HE settings has become quite unruly and is characterized by pedagogical solutions that do not have a stable connection to state-of-the-art theory, and that might lead to naive, simplistic, and essentialist understandings of 'culture' and 'the other'. Could it be that, considering the extreme popularity of interculturality in HE curricula across countries, teachers with little expertise in the area end up having to address it in the classroom? Could it be that teachers with a very good understanding of the developments in the field struggle to come up with activities to achieve the desired learning outcomes? We see that our Special Issue could be helpful to both those with little experience as well as to those wishing to expand their repertoire and experiment with new approaches and activities.

Our intention is not to set up a duality between an essentialist and nonessentialist camp: the field of intercultural communication is multidisciplinary and made up of a variety of both diverse and complementary perspectives. What we

\footnotetext{
${ }^{1}$ The corresponding author: Mélodine Sommier, University of Jyväskylä, Finland (melodine.c.m.sommier@jyu.fi).
} 
want to foreground is that, as teachers, we have a joint ethical responsibility towards our students to offer them the tools to interrogate and revise pervasive simplistic accounts about the 'Other' (see Dervin, 2011, pp. 37-38). Our discussion of teaching practices is founded on an understanding that these have a moral and social significance that extends way beyond the classroom. This holistic approach goes beyond exploring intercultural communication and intercultural education as isolated curriculum areas and takes us straight to praxis that we define after Kemmis and Smith (2008) as 'elevated' (p. 4) or morally committed action undertaken in professions such as teaching. Teaching praxis entails considering not only one's own interests but also potential long-term consequences for our students and for society at large (Kemmis \& Smith, 2008). Despite their ostensibly benevolent intentions, unreflexive intercultural communication teaching practices might have significant repercussions as they reproduce social divisions and inequalities rather than promote unbiased curiosity, respect, connecting, solidarity, and social justice. In this sense, the gap that we detect-between transformative theory and essentializing practices - could be seen as one manifestation of the dialectics of 'transformational social justice versus the reproduction of social inequalities' that the Editors of JPHE highlighted as 'the most enduring tension within higher education systems' (Aarnikoivu et al., 2019, p. 2).

If enduring dialectics are at the core of our problem, how could we possibly address it? We engage with the notion of praxis as theoretically informed practices that are both constituted in, but also constitutive of, the broader social and political context. While we construct our teaching practices from the theoretical resources available to us, our practices are also constructive of different versions of the world. This understanding implies that teaching practices have potential for social transformation. With this special issue we aim to open up a critical discussion on pedagogical tools and approaches available to us to help us align intercultural education praxis with state-of-the-art theory in ways that genuinely assist our students in engaging 'positively, creatively and critically' (Holliday, 2016, p. 329) with the people and social realities that they encounter in their everyday lives.

We find that understanding the disconnect between transformative theory and essentializing practices calls for unearthing several subsets of contradictionsinterdependent and mutually exclusive developments, trends, and interests (see Putnam, Fairhurst, \& Banghart, 2016) at the intersections of which intercultural education praxis emerges. These contradictions unfold on pedagogical, disciplinary, and institutional levels, and these levels are all addressed by the contributions in this special issue. 


\section{Navigating pedagogical contradictions: Between addressing social injustice and being inclusive}

The pedagogical objectives we set for our teaching and how we negotiate them with our students constitute one significant tension underpinning intercultural education praxis. Critical intercultural communication scholars would agree that intercultural education should sensitize students to the discursive character of social hierarchies, the inequitable distribution of power, and how injustice comes to pivot on presumed essentialized group membership. At the same time, we need to make sure that our students can actually relate to our content. Many students, having already been exposed to intercultural washing - institutional discourses conveying misleading impressions regarding the importance placed on interculturality-might harbor very different expectations for a course in intercultural communication. Some might also find themselves singled out, disheartened, or alienated by the critical discourse.

Teaching based on solid understandings of culture has been criticized for providing incomplete pictures of what intercultural communication entails (e.g., Dervin, 2010; Kundnani, 2004; Piller, 2017). Designed to provide easy ready-made solutions, such teaching builds on monolithic and essentialist views of culture and 'the other' which present intercultural communication as disconnected from societal, historical, and political tensions (Holliday, 2010). Consequently, this pedagogical approach to intercultural communication often reiterates typical pitfalls of banal nationalism which reduce culture to (dominant) national discourses (Billig, 1995). In contrast, critical intercultural communication conceptualizes culture as a dynamic and multi-layered notion that encompasses the intersection of different social and cultural dimensions (Piller, 2017). Critical intercultural communication sheds light on the interplay between layers of social and cultural dimensions that contribute to (re)producing power inequalities, and, most importantly, challenges dominant narratives that try and erase the exclusionary dimension of culture (Piller, 2017).

Given the popularity of essentialist narratives, many of our students' firstor only-understanding of intercultural communication is limited to post-positivist models of intercultural competence, essentialist shortcuts about national culture, celebratory rhetoric of diverse customs, traditions, and food practices, watereddown discourses about clashing civilizations, or convenient lists of dos and don'ts. As a result, teachers trying to implement critical intercultural teaching can find it difficult to meet their students' expectations regarding what this entails. Critique of mainstream taken-for-granted notions of culture and identity might appear not only as difficult to grasp but also as normative, patronizing and dismissive of students' previous knowledge and language available to them to explain the world. This 
might lead to a sense of insecurity and fear that everything one says is essentialist, and therefore wrong. In other words, when carelessly wielded, criticism may become an oppressive teaching practice. Dervin and Gross (2016) share a relevant viewpoint that is worth highlighting to our students and embracing in our teaching: failure is a natural part of life. There may be episodes in our unfolding interactions where we simply cannot meet the 'noble objectives' (p. 5) of non-essentialism, no matter how hard we try. While non-essentialism is something we should strive for, we should also accept that in our everyday interactions we are constantly navigating between simplistic and complex views of persons and the social world-or simplexifying (Dervin \& Gross, 2016).

Renegotiating with our students what the field is about introduces an added level of challenges and dilemmas that pertain to the dynamics of classroom interaction. Many of the issues we discuss in our teaching are uncomfortable because they are not disconnected from us; we cannot discuss matters of inequalities in social status, power, and agency in the social world without acknowledging that these issues touch everyone participating in the teaching situation. We face the delicate task of addressing social inequalities often connected to some specific presumed group memberships while making sure that we are not imposing victim or oppressor identities on people in the group, and, through this, reinforcing divisions. We can see how this task could be accomplished through sensitizing our students about the complexity and intersectionality of our identities, or what Dervin (e.g., 2016) has called diverse diversities. We are all different in different ways, and at different points in time 'even the powerful can find themselves in powerless positions because of some of their identities, changes in life circumstances, illnesses, and so on' (Dervin, 2016, p. 28). Social interactions are complex and fluid, and so are the differences that we might talk into being in interaction. Even more so, it is helpful to consider how we could turn our focus away from differences and towards commonalities and ways of connecting to the other person that Holliday and Amadasi (2020) term finding non-essentialist threads. While we address dire social group-based inequalities, we should at the same time support our students towards acknowledging that a constructive and transformative dialogue could be one where everyone is invited and included.

\section{Navigating disciplinary contradictions: Between popularity and theoretical sophistication}

The field of intercultural communication has been undergoing a transformation towards nuanced and critical understandings of 'culture' and 'communication' in ways so profound that one could talk of a paradigmatic shift (see, e.g., Ferri, 2018). 
Meanwhile, the notion of the intercultural has also been attracting broad popular interest, and actors across social domains have claimed ownership of intercultural expertise. Sadly, it is not the critical but rather the essentialist variant that has been capturing the popular imagination. While it is undeniably important for a field to gain broad recognition, the watering down and simplification of its concepts undermine its status and social objectives.

In retracing the genesis of the field of intercultural communication, Moon (1996) revealed the critical and political dimension of the discipline in the 1970s. Overtaken by cross-cultural research in the 1980 s, intercultural communication was reinvested by the study of power and various dimensions of (social and cultural) differences from the 1990s onwards. Since then, critical intercultural communication has moved away from the shadow and the margins and gained increasing attention and credibility. Over the years, landmark publications have underlined the academic and societal relevance of critical intercultural scholarship (e.g., Halualani, Mendoza, \& Drzewiecka, 2009) and outlined its main tenets (e.g., Dervin, 2011; Holliday, 1999; Nakayama \& Halualani, 2010; Piller, 2012, 2017).

In spite of this, the heyday of cross-cultural communication is not over, and its legacy is a challenge for intercultural communication, particularly in the context of teaching and implementation in HE. Especially problematic within the intercultural communication field is the solid or essentialist view of culture as an objectively describable system of cognitive and behavioral traits (most typically, territorially bound to the nation-state) that defines all the persons seen as belonging to the group. Intuitively appealing and offering the promise of the quick fix, the essentialist notions of culture have become and remain prominent in public discourses where different actors and media products tap into limited and restrictive understandings of 'cultural' identities and practices (see, e.g., Breidenbach \& Nyíri, 2009; Sommier, 2018).

Although the field of intercultural communication is moving away from solid understandings of culture, in alignment with the bigger paradigm shift in the humanities and social sciences (see, e.g., Bauman, 2012), HE institutions and educational curricula often fail to incorporate the latest theoretical development and, in this sense, display a lack of immunity to prevalent essentialist discourses. This problem is compounded by the fact that HE institutions have been increasingly eager to position themselves as international actors. Needless to say, the concept of interculturality has become an important discursive tool in such efforts. Global, international, and intercultural dimensions have been increasingly introduced to HE curricula across disciplines falling on rationales as disparate as ensuring individual, institutional, and national competitiveness, and supporting global civic engagement (Horn, Hendel, \& Fry, 2012). Several disciplines, such as business and management, language, or health education (Breidenbach \& Nyíri, 2009; Dervin \& 
Tournebise, 2013), as well as trainings and advice provided prior to or during exchange periods (Dervin \& Layne, 2013; Santoro, 2014), draw on and reproduce the popular essentialist notions or engage with a Janusian vision (Dervin, 2011) that uncritically combines essentialist and non-essentialist understandings of culture.

The status of interculturality at tertiary level is therefore characterized by a prominent gap between state-of-the-art theory and practice, and, despite good intentions, 'most intercultural education practice supports, rather than challenges, dominant hegemony, prevailing social hierarchies, and inequitable distributions of power and privilege' (Gorski, 2008, p. 1). This situation is detrimental to both HE institutions and the field of intercultural communication, and both sides can benefit from moving past 'intercultural-washing' practices which decisively present interculturality as a focus area of HE institutions. However, doing this requires the field of intercultural communication to overcome internal tensions. On the one hand, theoretical rigor and intellectual leadership are needed for the field to commit to non-essentialism and gain visibility. On the other hand, critical intercultural communication scholars should keep on widening the scope and direction of their work while engaging in interdisciplinary collaboration for pedagogical development, design, and practice.

\section{Navigating institutional contradictions: Between social responsibility and 'intercultural washing' discourses.}

The gap between theory and teaching practices, and the assumed challenges of bringing critical views into the classroom, are often attributed to pitfalls of critical (intercultural) scholarship: too abstract, too complex, too disconnected from lived realities. However, critical intercultural communication is about power, struggles, and inequalities, all of which permeate our everyday lives. Being blind to these issues does not mean they are absent; it reveals our own privileges. Rather than the inadequacy of critical intercultural scholarship to capture everyday experiences, we want to point to the inadequacy of HE institutions, as privileged institutions, to address the complexities of everyday experiences and provide room for nonnormative teaching practices. More specifically, we want to highlight the tensions that, based on our experiences, seem to characterize at least many European HE institutions, torn between their status as social actors and the criticisms they face for being ivory towers, conflicted between their position as venues for intellectual leadership and the neo-essentialist discourses they (re)produce (see also Aarnikoivu et al., 2019).

As mentioned thus far, limitations regarding the status of intercultural communication teaching at tertiary education are connected to struggles in the 
classrooms as well as within the discipline. However, addressing these alone only provides incomplete picture and solutions, for renewing intercultural education needs to be addressed in light of structural issues. Teaching practices in HE largely depend on the structures that allow and constrain them, including, for instance, internal and external financial pressure, precarious teaching positions, top-down curricula developments, and neoliberal and market-driven curricula developments (Wheaton, 2020). Many intercultural developments in HE revolve around international exchanges and efforts to decolonize curricula. Although these are noble efforts, defining diversity and interculturality only through these isolated aspects conveys false impressions regarding how interculturally sound HE institutions are. Such 'intercultural-washing' discourses may however fit the selfnarrative of globalized, attractive, and forward-facing HE institutions. In order to go beyond such limited (and limiting) discourses, and therefore allow for critical and meaningful intercultural education, HE institutions need to produce discourses about diversity that encompass more than international mobility-which is itself embedded in privileged discourses of a globalized elite-and notice as well as incorporate a diverse body of practitioners and students.

Discourses about diversity in $\mathrm{HE}$ often remain limited to national backgrounds and embedded in a Eurocentric vision that perpetuates the conflation of diversity with exotic otherness. Yet, critical intercultural scholars would agree that diversity needs to be addressed along several social dimensions and has to (also) be about us here and now. Intercultural communication and diversity keep being constructed by HE institutions through Others-such as the exotic and lucrative figure of the international student. This reveals the extent to which much of those in charge of the narratives produced by HE institutions are of a similar background. We find problematic how the intercultural element is used unreflexively, for instance as synonymous with the heralded keywords of diversity and internationalization (see Cole \& Meadows, 2013). The intercultural can be nothing but an empty marketing buzzword. In his ethnographic study set in a large British university, Collins (2018) reflects on the institutionalization of the intercultural and demonstrates how what he calls 'interculturality from above' becomes aligned with the neoliberal ideology as a trendy but empty term used for self-branding. Such use of the intercultural appears to be blissfully disconnected from the social and political global conditions, concealing both dire inequalities as well as commonalities and connections among people (Collins, 2018). Re-shaping discourses about diversity and interculturality produced by HE institutions is therefore central to providing a safe avenue for meaningful intercultural education to be implemented.

Subjected to neoliberal ideologies governing (globalized) education, HE institutions often produce limited and limiting tales of a diverse body of students 
(and employees) which drastically overlook social class, 'race', gender, family status, technological literacy, language competences, physical ability, or sexuality. Incidentally, many of the pitfalls mentioned here can find solutions in (intercultural) research and meaningful intercultural communication education. It therefore seems ironic that HE institutions are giving rise to critical scholarship while overlooking the findings it puts forth and, at times, even producing competing discourses. Addressing this tension seems of particular importance in light of post-truth, disinformation, and anti-intellectualism movements targeting $\mathrm{HE}$ and adding to the external pressure they are under (see, e.g., Gülen, 2021). The privileges that still characterize many $\mathrm{HE}$ institutions seem to facilitate their positioning as disconnected from historical and political trajectories that shape the rest of society. In failing to grapple with its own privilege and the role it plays in (re)producing societal inequalities, HE also fails to fulfill its role as a societal actor and instead fulfills the prophecy of HE institutions being ivory towers. Thus, engaging with privilege and oppression within and outside of HE, and in light of political, historical, and structural elements, seems of critical importance to enable critical scholarship and education practices to take hold.

\section{Contributions in this special issue}

The contributions in this special issue endeavor to address the gap between theory and practice of intercultural education. This special issue comprises one invited opinion paper and seven articles that approach the theme of how to apply critical intercultural education at tertiary level from various perspectives. More specifically, this special issue aims to make its contribution to the theoretical discussion about the notion of critical intercultural education as well as to offer concrete precepts to implement it in practice. The first two articles offer a theoretical foundation to address critical intercultural communication in HE. In the articles, the authors discuss the challenges and opportunities related to incorporating critical intercultural education at Universities. Articles three and four, in turn, examine the topic of critical intercultural education predominantly from the teachers' and researchers' perspective. These articles provide useful insights into the discourse and practices of HE faculty related to everyday communication and supervision. Finally, articles five to seven rely on empirical data from courses where students have engaged with critical intercultural education and offer valuable and concrete examples of how to approach the topic in practice in HE.

Jolanta Drzewiecka's invited opinion paper lays the ground for this special issue. In it, the author reflects on the current issues and trends in critical intercultural communication and draws on her personal experiences of living in different 
continents. Drzewiecka argues for focusing on related concepts in addressing interculturality in the classrooms, namely diversity, 'race', and decoloniality. She urges readers to focus on differences within national contexts, which helps to deconstruct the connection between nation and culture and also bring power relations to the forefront. Moreover, Drzewiecka stipulates that more attention should be placed on 'race' and how it can work as a technology of power and exclusion. She promotes the argument that students should be equipped with skills to critically examine the manifestations of 'race' in every layer of society. Finally, Drzewiecka calls for greater attention to the colonial history of Europe in order to develop historical awareness of how the colonial past is mirrored in the present day. In the paper, Drzewiecka elaborates on the above focal points and suggests that they can provide a map for designing a progressive critical intercultural communication curriculum.

The first article by Katri Jokikokko focuses on building a genuinely intercultural higher education learning community that provides equal learning possibilities for all. By engaging in a literature review, Jokikokko raises institutional racism and discrimination, monolingual higher education policies, as well as neoliberal educational agendas as the main challenges for creating such a learning environment. She further argues that interculturality should be addressed at a macro-level and incorporated in the strategies, policies, and curricula of higher education institutions. Jokikokko also highlights the importance of intercultural competence, or lack thereof, and how this should be addressed and supported both from the perspectives of the students and staff. The questions to ask oneself as actors in higher education to reflect on 'the current "intercultural" situation' in the institution outlined by the author have the potential to create positive change and to develop more equal and socially just practices in higher education.

In the second article, Margarethe Olbertz-Siitonen focuses on practical applications of naturalistic inquiry in intercultural education. The author aptly remarks that although more modern views of culture that distance themselves from the traditional essentialist understanding have become mainstream, the concrete and tangible solutions to apply critical intercultural lenses in higher education often remain rare. In the article, Olbertz-Siitonen offers her contribution to the issue, and advocates for the use of naturalistic inquiry to address interculturality. She argues that naturalistic inquiry enables students to analyze culture in real-life encounters and free from theoretical presuppositions, which correspondingly can help them to build a more nuanced understanding of culture and uncover potentially hidden aspects of it.

The third article, written by Daniel Rellstab, deals with how the notion of culture is addressed and discussed by German researchers and university teachers. This action research article draws on data collected from a two-day workshop for 
researchers and educators of German as a second language (L2) in West Africa in 2019 in which the author also participated. By applying nexus analysis, the author showcases how people are very careful and avoid simplistic conceptualizations when discussing the concept of culture in isolation. However, as Rellstab's data interestingly reveals, in more informal situations, people tend to fall back into a discourse that reflects more traditional views on culture. The author suggests the benefits of analyzing our talk in various communicative situations and what it reveals about our discourse practices.

Richard Fay, Jane Andrews, Zhuo Min Huang, and Ross White discuss the need to develop a critical intercultural supervisory culture in the fourth article of this special issue. The authors use Anglophone UK universities as their context and propose that critical intercultural supervision praxis should be considered in two interrelated strands, namely the role of languages in research and research as knowledge-work. The authors further argue that there should be a shift from an instrumental, operational focus to a more critical stance in both strands. More specifically, Fay, Andrews, and Huang advocate for researchers to develop a translingual mindset which aims for a greater awareness of the role of linguistic features and language preferences in research. Additionally, the authors discuss epistemic injustice and how that may manifest in research and propose principles to address this. To conclude, the authors offer some insightful recommendations to facilitate a critical intercultural supervisory culture, such as researcher activism and inclusion of critical intercultural thinking into the research codes of practice of various institutions.

Kristin Rygg, Paula Rice, and Anne Linda Løhre's article appears as the fifth article of the special issue. The authors argue that, in addition to criticizing the traditional approach to intercultural communication, there is a need for creating concrete teaching activities that can be used to provide students with more critical understanding of cultural encounters. In their article, the authors make their contribution to this by discussing alternative interpretations as a learning outcome in teaching intercultural communication. The authors used their case study on a ship building project between the Norwegian Royal Navy personnel and the South Korean shipyard personnel in three different university courses in business studies. The authors suggest that by not providing the students with any a priori theories on cultural differences, they were better able to identify the effect of various contextual factors such as occupation, age, previous experience, language proficiency, and perspective on the interaction and communication between the shipbuilders. The authors also aptly point out that these types of activities feed into contemporary teaching approaches such as student led inquiry.

The sixth article, by Chantal Crozet, Kerry Mullan, Jing Qi, and Masoud Kianpour, deals with teaching and learning about language, interculturality, and 
power from a critical perspective. The authors report on the findings of a qualitative research project of designing and delivering an Intercultural Communication course to tertiary students in Australia. The project was guided by the research question of: 'which aspects of society, identity, and self are at stake when teaching and learning about language, interculturality, and power from a critical perspective?' and relied on three sets of data, namely the course content; ethnographic notes from teaching staff meetings, tutors' interviews, and tutorial observation; as well as student feedback surveys and focus group discussions. The article demonstrates how there are multiple factors at play when taking on a critical approach to intercultural education, such as the students' diverse social, cultural, and linguistic capital as well as the teachers' varying level of engagement and knowledge for critical intercultural education.

In the seventh and final article, Jan Van Maele, Steven Schelkens, and Katrien Mertens report on a study in which a critical approach to intercultural communication is used in a module for engineering technology students, a context in which intercultural learning is often absent from the curricula. In the module, students in small teams engaged with people and practices that represent cultural strangeness to them. The study uses qualitative data (i.e. team reports) analyzed thematically to uncover the students' definitions of strangeness and the insights they perceive they have gained in their 'encounters with strangeness'. The students seemed to truly value the personal experience and engagement with others. Van Maele, Schelkens, and Mertens identified three main takeaways from the project from the students' perspective, namely keeping an open mind, avoiding essentialist views of culture, and being aware of stereotyping. Based on the results, the authors argue for the potential of using 'encounters with strangers' to examine different perspectives in a critical manner.

\section{Concluding words}

The tensions we mentioned here-in the classroom, at the disciplinary level, and in HE institutions - resonate with our understanding of praxis as a conceptual tool to unearth and engage with the political and societal dimension of knowledge formation and teaching practices in HE. Addressing the tensions discussed thus far is therefore meant to pave the way for enacting change at different (yet intertwined) levels by renewing intercultural education practices for both teachers and students. This is of importance to teachers who may not have the tools nor time to renew teaching practices and may find it challenging to meet students' expectations of intercultural communication. It is also of importance to students, to ensure all of them can recognize themselves in and benefit from intercultural education: students 
from the margins who are excluded from discourses about diversity produced by HE institutions, as well as students from dominant groups who do not recognize themselves in teaching materials where meanings and implications of normative discourses are not adequately problematized. While essentialist discourses are detached from students' empirical realities, critical intercultural teaching should be careful not to impose divisive identities on students but rather point to their diverse diversities and possibilities for connecting and finding threads.

Overall, the limitations of intercultural communication in $\mathrm{HE}$ hint at important shortcomings of HE institutions, but also at a lasting challenge for critical intercultural communication to make its theoretical tenets and societal relevance visible. Trapped between the looming legacy of cross-cultural communication and the grand aura of cultural studies, intercultural communication sometimes struggles to establish itself. The increasing attention paid to it in HE, albeit in a limited or misled manner, nevertheless offers opportunities to highlight how accessible and relevant critical intercultural communication is - not only for HE institutions, but for society. As a subject being taught but also as a subject being lived by HE actors and shaped by HE institutions, critical intercultural communication offers a powerful and much needed lens to rethink and renew tertiary education.

\section{Acknowledgements}

Finally, we as guest editors would like to conclude this editorial to the special issue by expressing our gratitude to the Handling Editors for the Special Issue, Kathleen Mahon and Lill Langelotz, whose dedication and devotion to this special issue were beyond compare. Furthermore, we would like to give our heartfelt thanks to all the anonymous scholars who kindly agreed to act as reviewers for the articles to ensure that this special issue was of the highest quality. 


\section{Author biographies}

Mélodine Sommier, Ph.D., is working as University Teacher in Intercultural Communication at the University of Jyväskylä (Finland). Her work concentrates on the use of culture as a discursive and an interactional resource. She mostly relies on critical and discursive approaches to examine the construction of cultural realities and outcomes regarding the (re)production of difference.

Malgorzata Lahti, Ph.D., works as Senior Lecturer in Communication at the Department of Language and Communication Studies, University of Jyväskylä, Finland. She has extensive experience designing and running courses in intercultural communication, and she has co-run international master's programmes (Intercultural Communication; Language, Globalisation and Intercultural Communication) offered at the department. Lahti's research interests include interculturality and multilingualism in professional and academic contexts, critical approaches to intercultural communication, and face-to-face and technology-mediated team interaction.

Anssi Roiha, Ph.D., works as University Lecturer in foreign language pedagogy at the University of Turku in Finland where he conducts research and trains pre-service teachers. He obtained his Ph.D. from the University of Jyväskylä, Finland on Content and Language Integrated Learning (CLIL). His other research interests include foreign language education, differentiated instruction and intercultural education. His most recent work has focused on language learners' self-beliefs with the use of visual narratives. 


\section{References}

Aarnikoivu, M., Mahon, K., Agnafors, M., Hoffman, D., \& Angervall, P. (2019). Another higher education journal: Really? Journal of Praxis in Higher Education, 1(1), 1-9. https://doi.org/10.47989/kpdc.vol1.1.2019

Bauman, Z. (2012). Liquid modernity. Malden, MA: Polity Press.

Billig, M. (1995). Banal nationalism. Los Angeles, CA: Sage.

Breidenbach, J., \& Nyíri, P. (2009). Seeing culture everywhere: From genocide to consumer habits. Seattle: University of Washington Press.

Cole, D., \& Meadows, B. (2013). Avoiding the essentialist trap in intercultural education. Using critical discourse analysis to read nationalist ideologies in the language classroom. In F. Dervin \& A. J. Liddicoat (Eds.), Linguistics for intercultural education (pp. 29-48). Amsterdam: John Benjamins Publishing.

Collins, H. (2018). Interculturality from above and below: Navigating uneven discourses in a neoliberal university system. Language and Intercultural Communication, 18(2), 167-183.

Dervin, F. (2010). Assessing intercultural competence in language learning and teaching: A critical review of current efforts. In F. Dervin \& E. SuomelaSalmi (Eds.), New approaches to assessment in higher education (pp. 157173). Bern: Peter Lang.

Dervin, F. (2011). A plea for change in research on intercultural discourses: A 'liquid' approach to the study of the acculturation of Chinese students. Journal of Multicultural Discourses, 6(1), 37-52.

Dervin, F. (2016). Interculturality in education: A theoretical and methodological toolbox. London: Palgrave Macmillan.

Dervin, F., \& Gross, Z. (2016). Introduction: Towards the simultaneity of intercultural competence. In F. Dervin \& Z. Gross (Eds.), Intercultural competence in education (pp. 1-10). London: Palgrave Macmillan.

Dervin, F., \& Layne, H. (2013). A guide to interculturality for international and exchange students: An example of Hostipitality? Journal of Multicultural Discourses, 8(1), 1-19. https://doi.org/10.1080/17447143.2012.753896

Dervin, F., \& Tournebise, C. (2013). Turbulence in intercultural communication education (ICE): Does it affect higher education? Intercultural Education, 24(6), 532-543. https://doi.org/10.1080/14675986.2013.866935

Ferri, G. (2018). Intercultural communication: Critical approaches and future challenges. London: Palgrave Macmillan.

Gorski, P. C. (2008). Good intentions are not enough: A decolonizing intercultural education. Intercultural education, 19(6), 515-525. 
Gülen, H. (2021, May 25). Anti-intellectualism as a reaction against the rise of minority politics - An interview with Éric Fassin. Hafiza Merkezi Berlin. https://www.hm-berlin.org/anti-intellectualism-as-a-reaction-against-therise-of-minority-politics-an-interview-with-eric-fassin/

Halualani, R. T., Mendoza, S. L., \& Drzewiecka, J. A. (2009). 'Critical' junctures in intercultural communication studies: A review. The Review of Communication, 9(1), 17-35.

Holliday, A. (1999). Small cultures. Applied Linguistics, 20(2), 237-264.

Holliday, A. (2010). Intercultural communication \& ideology. London: Sage.

Holliday, A. (2016). Difference and awareness in cultural travel: Negotiating blocks and threads. Language and Intercultural Communication, 16(3), 318-331. https://doi.org/10.1080/14708477.2016.1168046

Holliday, A., \& Amadasi, S. (2020). Making sense of the intercultural: Finding deCentred threads. London: Routledge.

Horn, A. S., Hendel, D. D., \& Fry, G. W. (2012). The empirical basis for adopting a civic rationale for internationalization. Higher Education, 64, 161-175. https://doi.org/10.1007/s10734-011-9485-0

Kemmis, S., \& Smith, T. J. (2008). Praxis and praxis development: About this book. In S. Kemmis \& Tracy J. Smith (Eds.), Enabling praxis: Challenges for education (pp. 3-14). Rotterdam: Sense.

Kundnani, A. (2004). The rise and fall of British multiculturalism. In G. Titley (Ed.), Resituating culture (pp. 105-112). Strasbourg: Council of Europe.

Moon, D. G. (1996). Concepts of 'culture': Implications for intercultural communication research. Communication Quarterly, 44(1), 70-84.

Nakayama, T. K., \& Halualani, R. T. (Eds.). (2010). The handbook of critical intercultural communication. Malden, MA: Wiley-Blackwell.

Piller, I. (2012). Intercultural communication: An overview. In C. B. Paulston, S. F. Kiesling, \& E. S. Rangel (Eds.), The handbook of intercultural discourse and communication (pp. 3-18). Wiley-Blackwell.

Piller, I. (2017). Intercultural communication: A critical introduction (2nd ed.). Edinburgh: Edinburgh University Press.

Putnam, L., Fairhurst, G., \& Banghart, S. (2016). Contradictions, dialectics, and paradoxes in organisations: A constitutive approach. The Academy of Management Annals, 10(1), 65-171. https://doiorg.eur.idm.oclc.org/10.5465/19416520.2016.1162421

Santoro, N. (2014). 'If I'm going to teach about the world, I need to know the world': Developing Australian pre-service teachers' intercultural competence through international trips. Race Ethnicity and Education, 17(3), 429-444. https://doi.org/10.1080/13613324.2013.832938 
Journal of Praxis in Higher Education, Special Issue, Vol. 3, No. 2 (2021)

Sommier, M. (2018). 'Culture' as a discursive resource in newspaper articles from Le Monde about secularism: Constructing 'us' through strategic oppositions with religion. Journal of Multicultural Discourses, 13(3), 283-299.

https://doi.org/10.1080/17447143.2018.1437161

Wheaton, A. (2020). Shift happens; Moving from the ivory tower to the mushroom factory. Higher Education Research \& Development, 39(1), 6780. 